JPH RECODE Vol. 1 No. 1 (2017)

\title{
GAMBARAN IKLIM KERJA DAN TINGKAT DEHIDRASI PEKERJA SHIFT PAGI DI BAGIAN INJECTION MOULDING 1 PT.X SIDOARJO
}

\author{
Anda Desi Puspita ${ }^{1}$, Noeroel Widajati \\ ${ }^{1}$ Program Studi Kesehatan Masyarakat, Fakultas Kesehatan Masyarakat, Universitas Airlangga \\ ${ }^{2}$ Departemen Keselamatan dan Kesehatan Kerja. Email: andes.3112@gmail.com
}

\begin{abstract}
The working environment at the Injection Moulding 1 PT.X Sidoarjo has hot work climate. The hot climate of the work comes from the heat generated by the production machines which are numerous. The hot working climate caused worker feels hot, a lot of sweat and can lead to dehydration. The purpose of this study was to analyze the work climate and levels of dehydration in the morning shift workers Injection Moulding 1 PT.X Sidoarjo. This study was an observational study with cross-sectional approach. The tools used to measure the WBGT was heatstress monitor Questemp 36 and the level of dehydration using urine specific gravity checks. The number of samples in this study is total population of about 31 workers who have met the criteria for inclusion are in good health, didn't have kidney disease and diabetes mellitus, and not menstruating or diarrhea. Data were analyzed descriptively and presented in tables and percentages. The results showed that the working climate in the Injection Moulding 1 supreme was 29,5 $5^{\circ}$ (exceeds the NAV) and 24 workers have pre dehydration. There was weak correlation between work climate and the level of dehydration (correlation coefficient: 0.204). Recommended to the company to add an electrolyte salt in drinking water and increase workers to access drinking water facilities. The company was also advisable to encourage workers regularly consume drinking water and to educate workers about the needs of body fluids for hot work environment.
\end{abstract}

Keywords: dehydration, work climate

\begin{abstract}
ABSTRAK
Lingkungan kerja di bagian Injection Moulding 1 PT.X Sidoarjo memiliki iklim kerja yang panas. Iklim kerja yang panas tersebut berasal dari panas yang dihasilkan oleh mesin produksi yang jumlahnya banyak. Iklim kerja yang panas menyebabkan pekerja terasa panas, banyak mengeluarkan keringat dan dapat mengakibatkan terjadinya dehidrasi. Tujuan dari penelitian ini adalah mempelajari iklim kerja dan tingkat dehidrasi pada pekerja shift pagi bagian Injection Moulding 1 PT.X Sidoarjo. Penelitian ini termasuk penelitian observasional dengan pendekatan cross-sectional. Alat yang digunakan untuk mengukur iklim kerja yaitu heatstress monitor Questemp 36 dan tingkat dehidrasi menggunakan pemeriksaan berat jenis urin. Jumlah sampel dalam penelitian ini yaitu total populasi sebanyak 31 pekerja yang telah memenuhi kriteria inklusi yaitu dalam kondisi sehat, tidak mempunyai penyakit ginjal dan diabetes mellitus, dan tidak sedang haid atau diare. Data yang diperoleh diolah secara deskriptif dan disajikan dalam bentuk tabel dan persentase. Hasil penelitian ini menunjukkan iklim kerja bagian Injection Moulding 1 tertingggi sebesar $29.5^{\circ} \mathrm{C}$ (melebihi NAB) dan 24 pekerja mengalami pre dehidrasi. Terdapat hubungan yang lemah antara iklim kerja dengan tingkat dehidrasi (koefisien 0,204). Saran kepada perusahaan untuk menambahkan garam elektrolit pada air minum pekerja dan meningkatkan fasilitas untuk mengakses air minum serta menganjurkan pekerja mengkonsumsi air minum secara teratur dan memberikan edukasi kepada pekerja tentang kebutuhan cairan tubuh untuk lingkungan kerja panas.
\end{abstract}

Kata Kunci: dehidrasi, iklim kerja

\section{PENDAHULUAN}

Faktor fisik dalam lingkungan industri lebih banyak memberikan pengaruh terhadap lingkungan pe sekitarnya dan berakibat langsung terhadap tenaga kerja, salah satu diantaranya adalah iklim kerja yang mencakup suhu udara, kelembaban, kecepatan gerak udara dan panas radiasi (Suma'mur, 2009).

Proses produksi suatu industri sering menghasilkan suhu yang tinggi, yang diperoleh dari sumber panas tertentu seperti mesin produksi, dapur peleburan baja, dapur peleburan gelas, dapur pembakaran keramik, dan lain sebagainya. Oleh karena itu, umumnya di dalam industri sering kita jumpai adanya perbedaan suhu yang besar antara satu tempat dengan tempat yang lain, dan hal ini mengakibatkan terjadinya perbedaan panas yang besar pula. Panas mempunyai pengaruh terhadap kesehatan tubuh manusia. Dalam kaitan ini, ada satu hal yang sangat penting untuk 
diketahui dari pekerja yang bekerja di lingkungan tempat mengeluarkan keringat, menurunkan produktivitas kerja kerja yang panas yaitu tentang sumber panas (Soeripto, dan kemungkinan besar dapat menyebabkan pekerja 2008). Salah satu sumber panas yaitu panas yang berasal mengalami dehidrasi. Dari hasil wawancara sebagian dari mesin produksi. Semakin banyak mesin yang ada besar pekerja mengalami keluhan seperti pusing, badan dalam proses produksi maka panas yang ditimbulkan cepat lelah, sering merasa ngantuk, tenggorokkan kering juga akan semakin besar.

Suhu lingkungan yang tinggi merangsang tubuh untuk berkeringat sebagai proses alamiah guna menurunkan suhu tubuh hingga pada suhu tubuh normal $\left(36^{\circ} \mathrm{C}-37^{\circ} \mathrm{C}\right)$. Pengeluaran keringat yang banyak tanpa diimbangi dengan asupan cairan yang cukup akan mengakibatkan dehidrasi yang juga bisa berakibat pada timbulnya kelelahan (Tarwaka, 2004). Dehidrasi adalah kehilangan cairan tubuh yang berlebihan karena penggantian cairan yang tidak cukup akibat asupan yang tidak memenuhi kebutuhan tubuh dan terjadi peningkatan pengeluaran air. Dehidrasi pada pekerja di tempat kerja perlu mendapatkan perhatian khusus karena dehidrasi dapat mempengaruhi biaya, produktivitas, dan keselamatan kerja. Ada banyak manfaat yang didapat jika tubuh terhidrasi dengan baik dan ketika sedang sibuk bekerja, perlu dipastikan bahwa asupan cairan yang masuk dalam tubuh cukup (Derbyshire, 2011).

Penelitian di Australia pada buruh tambang bawah tanah dengan suhu lingkungan kerja $36,2^{\circ} \mathrm{C}$ menunjukkan bahwa $60 \%$ pekerja memulai shift bekerja dalam keadaan dehidrasi (Brake, 2003). Penelitian lain di Australia pada pekerja outdoor menunjukkan bahwa $79 \%$ pekerja mengalami dehidrasi (Miller dan Bates, 2007). Penelitian lain

yang dilakukan oleh Sari (2014), pada tenaga kerja bagian boiler di PT. Albasia Sejahtera Mandiri, Semarang menunjukkan bahwa ada pengaruh yang signifikan antara iklim kerja panas terhadap dehidrasi dengan nilai $\mathrm{p}$ value sebesar 0,023 atau $\mathrm{p} \leq 0,05$. Penelitian mengenai tingkat dehidrasi pada pekerja masih jarang dilakukan di Indonesia. Oleh karena itu peneliti bermaksud melakukan penelitian dengan mengangkat tema tersebut.

PT. X Sidoarjo merupakan perusahaan yang bergerak dibidang produksi plastic packaging atau kemasan plastik. Dalam proses produksi PT.X Sidoarjo menggunakan berbagai macam jenis mesin yang jumlahnya tidak sedikit, diantaranya adalah mesin injection moulding, mesin mixer, mesin giling, mesin stamping, chiller, compressor, dan condensing. Berdasarkan hasil survei pendahuluan yang dilakukan peneliti dengan melakukan pengukuran suhu ruang dibagian injection moulding 1, maka diperoleh hasil yaitu suhu didalam ruangan dibagian injection moulding 1 sebesar $35^{\circ} \mathrm{C}$. Selain itu, dibagian injection moulding 1 memiliki jumlah mesin produksi yang lebih banyak dibandingkan bagian yang lain yaitu terdapat 20 mesin, kemungkinan besar hal tersebut yang menjadikan suhu panas cukup tinggi. Panas yang dikeluarkan oleh mesin dapat memapar tubuh pekerja dan menyebabkan perubahan suhu dan tekanan panas pada tubuh pekerja, sehingga menyebabkan pekerja terasa panas, banyak

dan keringat berlebih, sehingga mempengaruhi kinerja

pekerja dibagian injection moulding 1 . Keluhan tersebut merupakan tanda-tanda awal seseorang mengalami dehidrasi. Oleh karena itu peneliti semakin bersemangat untuk melakukan penelitian terkait tingkat dehidrasi pekerja khususnya pekerja shift pagi dibagian injection moulding 1. Pada shift pagi suhu di lingkungan kerja akan meningkat karena terpapar langsung oleh sinar matahari yang dapat mempengaruhi iklim kerja dibagian injection moulding 1. Penelitian ini bertujuan untuk mengetahui bagaimana iklim kerja dan tingkat dehidrasi pekerja di bagian injection moulding 1 serta menganalisis hubungan iklim kerja dengan tingkat dehidrasi pada pekerja shift pagi bagian Injection Moulding 1 PT.X Sidoarjo.

\section{METODE}

Penelitian ini dilakukan dengan metode observasional dengan pendekatan cross sectional. Penelitian ini bersifat deskriptif kuantitatf. Tempat penelitian dilakukan di bagian injection moulding 1 PT. X Sidoarjo. Pengumpulan data dilakukan selama satu bulan yaitu pada bulan Mei - Juni 2015. Sampel yang digunakan adalah seluruh populasi pekerja dibagian injection moulding 1 yang berjumlah 36 orang pekerja, yang mana seluruh responden yang ada telah memenuhi kriteria inklusi yakni; dalam kondisi sehat, tidak menderita penyakit ginjal dan diabetes mellitus dan tidak sedang mengalami haid atau diare. Jumlah responden yang memenuhi kriteria inklusi sebesar 31 orang pekerja. Pengumpulan data dilakukan dengan teknik pengukuran, kuesioner, observasi, uji laboratorium dan pengumpulan data sekunder. Pengukuran dilakukan untuk memperoleh data mengenai iklim kerja dibagian injection moulding 1. Alat yang digunakan untuk mengukur iklim kerja ialah heatstress monitor Questemp ${ }^{0} 36$. Kuesioner dan observasi dilakukan untuk memperoleh data mengenai karakteristik pekerja di bagian injection moulding 1 . Uji laboratorium dilakukan untuk memperoleh data tingkat dehidrasi dengan pemeriksaan berat jenis urin pekerja shift pagi dibagian injection moulding 1. Alat yang digunakan untuk pemeriksaan berat jenis urin ialah urinometer merk Urisys 1100 Roche. Kategori tingkat dehidrasi pekerja dibedakan berdasarkan nilai berat jenis urin. Kategori normal apabila nilai berat jenis urin $<1,015$. Pre dehidrasi tingkat ringan apabila nilai berat jenis urin 1,016 - 1,020. Pre dehidrasi tingkat sedang apabila nilai berat jenis urin $1,021-1,025$. Dehidrasi apabila nilai berat jenis urin 1,026 - 1,030. Dehidrasi berat atau klinis apabila nilai berat jenis urin $>1,030$. Data sekunder digunakan untuk memperoleh data pendukung profil 
perusahaan. Variabel yang diteliti adalah karakteristik Masa Kerja pekerja yang terdiri dari umur, masa kerja, waktu

Masa kerja pekerja pada penelitian ini dibagi istirahat dan konsumsi air minum, iklim kerja dan tingkat menjadi dua yaitu 4 - 12 tahun dan 13 - 21 tahun. Masa dehidrasi pekerja. Teknik pengolahan data menggunakan kerja pekerja dibagain injection moulding 1 antara 4 - 12 uji statistik koefisien korelasi. Data hasil penelitian tahun sebanyak 16 orang pekerja. Sedangkan masa kerja disajikan dalam bentuk tabel frekuensi dan persentase. antara 13 - 21 tahun sebanyak 15 orang pekerja.

\section{HASIL}

Berdasarkan hasil kuesioner, observasi, pengukuran dan data sekunder dari perusahaan diperoleh data dibagian injection moulding 1 sebagai berikut :

\section{Karakteristik Pekerja}

\section{Waktu Istirahat}

Waktu istirahat pekerja dalam penelitian ini dibedakan menjadi tiga. Waktu istirahat kurang apabila pekerja memiliki waktu istirahat $<30$ menit selama 8 jam kerja. Waktu istirahat cukup apabila pekerja memiliki waktu istirahat antara 30 menit s/d 1 jam selama 8 jam kerja. Waktu istirahat lebih apabila pekerja memiliki waktu istirahat $>1$ jam selama 8 jam kerja. Pekerja Karakteristik pekerja adalah gambaran umum yang dibagian injection moulding 1 yang memiliki waktu berkaitan dengan individu sebagai obyek penelitian, yaitu istirahat kurang sebanyak 4 orang, yang memiliki waktu pekerja shift pagi di bagian IM1 PT.X Sidoarjo. istirahat cukup sebanyak 19 orang dan yang memiliki Karakteristik pekerja di bagian injection moulding 1 PT.X waktu istirahat lebih sebanyak 8 orang.

Sidoarjo ini dibagi beberapa jenis yaitu umur pekerja, masa kerja pekerja, waktu istirahat pekerja dan konsumsi Konsumsi Air Minum air minum pekerja. Berikut ini data mengenai karakteristik pekerja di bagian injection moulding 1:

\section{Umur}

Konsumsi air minum pekerja selama 8 jam bekerja dalam penelitian ini dibagi menjadi dua. Konsumsi air minum yang sesuai apabila mengkonsumi air minum minimal 200 sampai dengan $300 \mathrm{ml}$ tiap 30 menit sekali.

Kelompok umur pekerja dibedakan menjadi dua, Tidak sesuai jika mengkonsumsi air minum kurang dari yaitu umur $\leq 40$ tahun dan $>40$ tahun. Kelompok umur 200 sampai dengan $300 \mathrm{ml}$ tiap 30 menit sekali. pekerja pada bagian injection moulding $1 \leq 40$ tahun Konsumsi air minum pekerja dibagian injection moulding sebanyak 29 orang pekerja dan kelompok umur > 401 yang sudah sesuai sebanyak 6 orang pekerja. Konsumsi tahun sebanyak 2 orang pekerja. air minum pekerja yang tidak sesuai sebanyak 25 orang pekerja.

\section{Iklim Kerja}

Hasil pengukuran iklim kerja di bagian injection moulding 1 menunjukkan ISBB terendah sebesar $28,40^{\circ} \mathrm{C}$ dan ISBB tertinggi sebesar $29,50^{\circ} \mathrm{C}$. Berdasarkan hasil pengukuran ISBB tersebut melebihi nilai ambang batas (NAB) iklim kerja untuk kategori beban kerja sedang yaitu sebesar $28^{\circ} \mathrm{C}$.

\section{Tingkat Dehidrasi Pekerja}

Tingkat dehidrasi pekerja dibagi menjadi 3 kategori yaitu normal apabila nilai berat jenis urin $<1,015$, pre dehidrasi (dehidrasi ringan apabila nilai berat jenis urin 1,016 -0 1,020 dan dehidrasi sedang apabila nilai berat jenis urin 1,021-1,025), dan dehidrasi apabila nilai berat jenis urin 1,026 -1,030

Hasil pengukuran berat jenis urin menunjukkan hanya satu pekerja yang memiliki status normal. Terdapat 24 pekerja yang mengalami pre dehidrasi (18 pekerja mengalami pre dehidrasi ringan dan 6 pekerja mengalami pre dehidrasi sedang). Sedangkan sisanya sebanyak 6 pekerja mengalami dehidrasi.

\section{Hubungan antara Umur Pekerja dengan Tingkat Dehidrasi Pekerja \\ Berikut ini hasil tabulasi silang antara umur pekerja dengan tingkat dehidrasi pekerja:}

Tabel 1. Persentase tingkat dehidrasi berdasarkan umur pekerja di PT.X Sidoarjo tahun 2015

\begin{tabular}{|c|c|c|c|c|c|c|c|c|c|c|}
\hline \multirow{3}{*}{$\begin{array}{l}\text { Umur } \\
\text { (tahun) }\end{array}$} & \multicolumn{6}{|c|}{ Tingkat Dehidrasi } & & & \multirow{2}{*}{\multicolumn{2}{|c|}{ Total }} \\
\hline & \multicolumn{2}{|c|}{ Normal } & \multicolumn{2}{|c|}{ Pre Dehidrasi Ringan } & \multicolumn{2}{|c|}{ Pre Dehidrasi Sedang } & \multicolumn{2}{|c|}{ Dehidrasi } & & \\
\hline & $\mathrm{N}$ & $\%$ & $\mathrm{n}$ & $\%$ & $\mathrm{~N}$ & $\%$ & $\mathrm{n}$ & $\%$ & $\mathrm{n}$ & $\%$ \\
\hline$\leq 40$ & 1 & 3,4 & 17 & 58,6 & 5 & 17,2 & 6 & 20,7 & 29 & 100 \\
\hline
\end{tabular}

Sumber: data primer

Berdasarkan hasil tabulasi silang antara umur

bahwa pekerja yang memiliki umur $\leq 40$ tahun pekerja dengan tingkat dehidrasi pekerja dapat diketahui sebanyak 17 orang $(58,6 \%)$ mengalami pre dehidrasi 
ringan. Pekerja yang memiliki umur $>40$ tahun sebanyak 2 orang dan masing-masing mengalami pre dehidrasi ringan satu orang $(50 \%)$ dan pre dehidrasi sedang satu orang $(50 \%)$. Tingkat keeratan hubungan antara umur pekerja dengan tingkat dehidrasi pekerja menunjukkan nilai koefisien korelasi sebesar 0,218. Terdapat hubungan yang lemah antara umur pekerja dengan tingkat dehidrasi pekerja.

\section{Hubungan antara Masa Kerja dengan Tingkat Dehidrasi Pekerja}

Berikut ini hasil tabulasi silang antara masa kerja pekerja dengan tingkat dehidrasi pekerja :

Tabel 2. Persentase tingkat dehidrasi berdasarkan masa kerja di PT. X Sidoarjo tahun 2015

\begin{tabular}{cccccccccccc}
\hline \multirow{2}{*}{ Masa Kerja } & \multicolumn{10}{c}{ Tingkat Dehidrasi } & \multicolumn{1}{c}{ Total } \\
\cline { 2 - 10 } & Normal & \multicolumn{1}{c}{ Pre Dehidrasi Ringan } & Pre Dehidrasi Sedang & Dehidrasi & \\
\hline & $\mathrm{N}$ & $\%$ & $\mathrm{n}$ & $\%$ & $\mathrm{~N}$ & $\%$ & $\mathrm{n}$ & $\%$ & $\mathrm{n}$ & $\%$ \\
\hline 4 - 12 tahun & 1 & 6,2 & 9 & 56,2 & 4 & 25 & 2 & 12,5 & 16 & 100 \\
\hline 13 - 21 tahun & 0 & 0 & 9 & 60 & 2 & 13,3 & 4 & 26,7 & 15 & 100 \\
\hline
\end{tabular}

Koefisien Korelasi : 0,110

Sumber: data primer

Berdasarkan hasil tabulasi silang antara masa pekerja menunjukkan nilai koefisien korelasi sebesar kerja pekerja dengan tingkat dehidrasi pekerja dapat 0,110 . Terdapat hubungan yang lemah antara masa kerja diketahui bahwa pekerja yang telah bekerja antara 4 - 12 pekerja dengan tingkat dehidrasi pekerja.

tahun sebanyak 9 orang $(56,2 \%)$ mengalami pre dehidrasi ringan. Pekerja yang telah bekerja antara 13 - Hubungan antara Waktu Istirahat dengan Tingkat 21 tahun sebanyak 9 orang $(60 \%)$ mengalami pre Dehidrasi Pekerja dehidrasi tingkat ringan. Tingkat keeratan hubungan Berikut ini hasil tabulasi silang antara waktu istirahat antara masa kerja pekerja dengan tingkat dehidrasi pekerja dengan tingkat dehidrasi :

Tabel 3. Persentase tingkat dehidrasi menurut waktu istirahat di PT. X Sidoarjo tahun 2015

\begin{tabular}{|c|c|c|c|c|c|c|c|c|c|c|}
\hline \multirow{3}{*}{ Waktu Istirahat } & \multicolumn{8}{|c|}{ Tingkat Dehidrasi } & \multirow{2}{*}{\multicolumn{2}{|c|}{ Total }} \\
\hline & \multicolumn{4}{|c|}{ Normal Pre Dehidrasi Ringan } & \multicolumn{2}{|c|}{ Pre Dehidrasi Sedang } & \multicolumn{2}{|c|}{ Dehidrasi } & & \\
\hline & $\mathrm{n}$ & $\%$ & $\mathrm{n}$ & $\%$ & $\mathrm{~N}$ & $\%$ & $\mathrm{n}$ & $\%$ & $\mathrm{n}$ & $\%$ \\
\hline Kurang & 0 & 0 & 1 & 25 & 1 & 25 & 2 & 50 & 4 & 100 \\
\hline Cukup & 0 & 0 & 13 & 68,4 & 3 & 15,8 & 3 & 15,8 & 19 & 100 \\
\hline Lebih & 1 & 12,5 & 4 & 50 & 2 & 25 & 1 & 12,5 & 8 & 100 \\
\hline
\end{tabular}

Koefisien Korelasi : 0,238

Sumber: data primer

Berdasarkan hasil tabulasi silang antara waktu memiliki waktu istirahat lebih sebanyak 4 orang (50\%) istirahat dengan tingkat dehidrasi pekerja dapat diketahui mengalami pre dehidrasi ringan. Tingkat keeratan bahwa pekerja yang memiliki waktu istirahat kurang hubungan antara waktu istirahat pekerja dengan tingkat sebanyak 2 orang (50\%) mengalami dehidrasi. Pekerja dehidrasi pekerja menunjukkan nilai koefisien korelasi yang memiliki waktu istirahat cukup sebanyak 13 orang sebesar 0,238. Terdapat hubungan yang lemah antara $(68,4 \%)$ mengalami pre dehidrasi ringan dan pekerja yang waktu istirahat pekerja dengan tingkat dehidrasi pekerja.

\section{Hubungan antara Konsumsi Air Minum dengan Tingkat Dehidrasi Pekerja}

Berikut ini hasil tabulasi silang antara konsumsi air minum pekerja dengan tingkat dehidrasi:

Tabel 4. Persentase tingkat dehidrasi berdasarkan konsumsi air minum pekerja di PT. X Sidoarjo tahun 2015

\begin{tabular}{|c|c|c|c|c|c|c|c|c|c|c|}
\hline \multirow{3}{*}{$\begin{array}{l}\text { Konsumsi Air } \\
\text { Minum }\end{array}$} & \multicolumn{8}{|c|}{ Tingkat Dehidrasi } & \multirow{2}{*}{\multicolumn{2}{|c|}{ Total }} \\
\hline & \multicolumn{2}{|c|}{ Norma } & Dehidrasi & Ringan & \multicolumn{2}{|c|}{ Pre Dehidrasi Sedang } & \multicolumn{2}{|c|}{ Dehidrasi } & & \\
\hline & $\mathrm{n}$ & $\%$ & $\mathrm{~N}$ & $\%$ & $\mathrm{n}$ & $\%$ & $\mathrm{n}$ & $\%$ & $\mathrm{n}$ & $\%$ \\
\hline Sesuai & 0 & 0 & 4 & 66,7 & 2 & 33,3 & 0 & 0 & 6 & 100 \\
\hline Tidak Sesuai & 1 & 4 & 14 & 56 & 4 & 16 & 6 & 24 & 25 & 100 \\
\hline
\end{tabular}

Koefisien Korelasi : 0,092

Sumber: data primer 
Berdasarkan hasil tabulasi silang antara konsumsi air minum pekerja dengan tingkat dehidrasi pekerja dapat diketahui bahwa pekerja yang mengkonsumsi air minum yang sudah sesuai sebanyak 4 orang $(66,7 \%)$ mengalami pre dehidrasi ringan. Pekerja yang mengkonsumsi air minum yang tidak sesuai sebanyak 14 orang (56\%) juga mengalami pre dehidrasi ringan. Tingkat keeratan hubungan antara konsumsi air minum pekerja dengan tingkat dehidrasi pekerja menunjukkan nilai koefisien korelasi sebesar 0,092. Terdapat hubungan yang lemah antara konsumsi air minum pekerja dengan tingkat dehidrasi pekerja.

\section{Hubungan antara Iklim Kerja dengan Tingkat Dehidrasi Pekerja}

Berikut ini hasil tabulasi silang antara iklim kerja dengan tingkat dehidrasi:

Tabel 5. Persentase tingkat dehidrasi berdasarkan iklim kerja di PT. X Sidoarjo tahun 2015

\begin{tabular}{ccccccccccc}
\hline \multirow{2}{*}{$\begin{array}{l}\text { Iklim } \\
\text { Kerja }\end{array}$} & \multicolumn{8}{c}{ Tingkat Dehidrasi } & \multirow{2}{*}{ Total } \\
\cline { 2 - 9 } & Normal & Pre Dehidrasi Ringan & Pre Dehidrasi Sedang & Dehidrasi & & \\
\hline$\leq$ NAB & 0 & 0 & 3 & 75 & 1 & 25 & 0 & 0 & 4 & 100 \\
\hline$>$ NAB & 1 & 3,7 & 15 & 55,5 & 5 & 18,5 & 6 & 22,3 & 27 & 100
\end{tabular}

Koefisisen Korelasi : 0,204

Sumber: data primer

Berdasarkan hasil tabulasi silang antara iklim kerja dengan tingkat dehidrasi pekerja di bagian injecton moulding 1 dapat diketahui bahwa pada iklim kerja yang melebihi nilai ambang batas sebanyak 15 orang $(55,5 \%)$ mengalami pre dehidrasi ringan, 5 orang $(18,5 \%)$ mengalami pre dehidrasi sedang dan 6 orang $(22,3 \%)$ mengalami dehidrasi. Iklim kerja yang masih dibawah nilai ambang batas juga terdapat pekerja yang mengalami dehidrasi, yaitu sebanyak 3 orang $(75 \%)$ mengalami pre dehidrasi ringan dan satu orang $(25 \%)$ mengalami pre dehidrasi sedang. Tingkat keeratan hubungan antara iklim kerja dengan tingkat dehidrasi pekerja menunjukkan nilai koefisien korelasi sebesar 0,204. Terdapat hubungan yang lemah antara iklim kerja dengan tingkat dehidrasi pekerja.

\section{PEMBAHASAN Umur}

Sampel yang digunakan dalam penelitian ini tidak ditentukan batasan umur. Kelompok umur pekerja di bagian injection moulding 1 kelompok umur $\leq 40$ tahun sebanyak 29 orang atau sebanyak $93,5 \%$ dari total populasi. Sedangkan pekerja yang berumur $>40$ tahun sebanyak 2 orang atau 6,5\% dari total populasi yang ada. Tenaga kerja yang berumur dibawah 40 tahun tergolong pekerja yang masih muda yang mana masih dapat mentolerir pengaruh suhu tinggi, karena pada usia muda lebih sedikit menyerap panas dan lebih cepat beraklimatisasi, tetapi juga tidak dianjurkan terlalu lama berada ditempat kerja yang bersuhu tinggi karena akan berakibat buruk terhadap kesehatannya. Menurut Siswanto (1991), bahwa pekerja yang berusia lebih dari 40 tahun sebaiknya tidak ditempatkan pada tempat kerja yang panas, karena kelenjar keringat menunjukkan respon yang lebih lambat terhadap beban panas metabolik dan lingkungannya.

\section{Masa Kerja}

Masa kerja pekerja di bagian injection moulding 1 PT.X Sidoarjo berdasarkan hasil penelitian pada tabel 1 diketahui bahwa masa kerja pekerja paling banyak yaitu masa kerja antara 4 sampai dengan 12 tahun sebanyak 16 orang atau sebesar 51,6\%, sedangkan pekerja yang memiliki masa kerja antara 13 sampai dengan 21 tahun sebanyak 15 pekerja. Masa kerja pekerja di bagian injection moulding 1 tersebut merupakan masa kerja yang panjang karena sudah lebih dari 10 tahun masa kerja. Semakin lama orang terpapar panas, semakin besar pula kemungkinan untuk mendapat keluhan kesehatan (Siswanto, 1991).

Pekerja yang memiliki masa kerja panjang tentunya sudah terbiasa berada di lingkungan kerja yang panas. Mereka sudah beraklimatisasi dengan lingkungan kerjanya. Namun apabila proses aklimatisasi sudah dilakukan dengan baik tidak menjamin pekerja tersebut akan terhindari dari risiko gangguan kesehatan akibat bekerja di lingkungan yang panas seperti dehidrasi. Tingkat dehidrasi seseorang tidak hanya ditentukan dari lamanya orang tersebut berada atau bekerja di tempat yang panas. Faktor penyebab dehidrasi bermacammacam, seperti kurangnya konsumsi cairan untuk tubuh, diet keras, dan akibat penyakit tertentu (diabetes, diare, infeksi pada kulit). Pada penelitian ini penentuan kelompok masa kerja juga kurang bervariasi seperti pada penentuan kelompok umur pekerja sebelumnya. Sehingga perbedaan lama kerja pekerja sulit untuk diketahui karena hanya beda satu angka yaitu 16 orang pekerja pada kelompok masa kerja 4-12 tahun dan 15 orang pekerja pada kelompok masa kerja 13-21 tahun.

\section{Waktu Istirahat}

Waktu istirahat pekerja dalam penelitian ini dibedakan menjadi tiga kategori yaitu kurang apabila istirahat $<30$ menit selama 8 jam kerja, cukup apabila istirahat antara 30 menit sampai dengan 1 jam selama 8 jam kerja dan lebih jika istirahat $>1$ jam. Berdasarkan 
hasil kuesioner diperoleh data sebanyak 19 orang pekerja lingkungan tempat kerja panas, dengan cara seperti itu atau 63,3\% memiliki waktu istirahat yang cukup, pekerja didorong untuk minum dalam jumlah sedikitsebanyak 8 orang pekerja atau $25,8 \%$ memiliki waktu sedikit tetapi sering dilakukan, misalnya satu gelas setiap istirahat yang lebih dan sebanyak 4 orang pekerja atau 20 sampai dengan 30 menit. Tenaga kerja yang hanya $12,9 \%$ memiliki waktu istirahat yang kurang.

minum bila merasa haus saja tidak akan memberikan hasil

Waktu istirahat pekerja shift pagi di bagian yang memuaskan. Tenaga kerja yang belum injection moulding 1 PT.X Sidoarjo ini pada pukul 11.00 beraklimatisasi sebaiknya mengkonsumsi air minum yang sampai dengan 12.00 WIB. Perusahaan telah mengandung garam dengan kadar $0,2 \%$, sedangkan menyediakan tempat istirahat khusus untuk para pekerja. pekerja yang sudah beraklimatisasi kadar garam dalam air Namun sedikit sekali pekerja yang memanfaatkan waktu minum sebesar $0,1 \%$, disesuaikan dengan kondisi yang istirahat di tempat tersebut, kebanyakan pekerja berada di kantin pada waktu istirahat. Pekerja memanfaatkan waktu istirahat mereka untuk makan siang dan melakukan ibadah sholat dzuhur.

Pekerja di bagian injection moulding 1 secara keseluruhan telah memiliki waktu istirahat yang sudah baik atau cukup yaitu antara 30 menit sampai dengan satu jam. Menurut Suma'mur (1988), menyatakan bahwa pekerjaan di lingkungan panas tidak boleh dilakukan secara terus-menerus tetapi harus diselingi dengan istirahat yang cukup, hal ini bertujuan untuk memberi kesempatan tubuh melakukan pemulihan.

\section{Konsumsi Air Minum}

Konsumsi air minum pekerja dalam penelitian ini dibagi menjadi dua yaitu konsumsi air minum yang sesuai apabila mengkonsumi minimal $200 \mathrm{ml}$ sampai dengan $300 \mathrm{ml}$ tiap 30 menit sekali dan tidak baik apabila mengkonsumsi air minum kurang dari $200 \mathrm{ml}$ sampai dengan $300 \mathrm{ml}$ tiap 30 menit sekali. Hasil kuesioner menunjukkan sebanyak 25 orang pekerja atau $80,6 \%$ pekerja mengkonsumsi air minum yang tidak sesuai dengan kebutuhan karena pekerja di bagian injection moulding 1 PT.X mengkonsumsi air minum kurang dari 200 sampai dengan $300 \mathrm{ml}$ tiap 30 menit sekali. Pekerja yang mengonsumsi air minum yang sudah sesuai hanya sebanyak 6 orang atau 19,4\% pekerja saja. Tidak heran apabila pekerja shift pagi di bagian injection moulding 1 mengalami dehidrasi.

Kebiasaan minum pada saat haus saja ataupun sewaktu-waktu adalah tidak baik, karena mekanisme haus sama sekali tidak adekuat untuk membujuk pekerja minum sesuai dengan jumlah cairan yang hilang melalui keringat, sehingga hal ini cenderung menuju ke defisit cairan. Mereka yang bekerja ditempat panas harus minum sesering mungkin (200 sampai dengan $300 \mathrm{cc}$ tiap 30 menit sekali). Hal ini bertujuan agar cairan tubuh tetap dalam keadaan seimbang (Siswanto, 1991). Namun ukuran 200 sampai dengan $300 \mathrm{cc}$ air tiap 30 menit sekali tersebut bukan menjadi patokan bahwa pekerja harus minum air sebanyak itu, melainkan yang terpenting adalah anjuran untuk minum air sesering mungkin untuk semua ukuran walaupun tidak 200 sampai dengan $300 \mathrm{cc}$ air.

Menurut Soeripto (2008), kehilangan air sangat banyak dari tubuh dalam bentuk keringat adalah untuk tujuan pendinginan dengan cara penguapan. Air minum harus disediakan bagi tenaga kerja yang bekerja di

\section{Iklim Kerja bagian Injection Moulding 1}

Menurut Kepmenaker (2011) Indesks Suhu Basah dan bola maksimal untuk waktu kerja $75 \%$ sampai dengan $100 \%$ pada beban kerja ringan adalah $30^{\circ} \mathrm{C}$ dan untuk beban kerja sedang adalah $28^{\circ} \mathrm{C}$. Beban kerja berat tidak ditolerir sama sekali untuk kerja $75 \%$ sampai dengan $100 \%$ sehingga tidak memiliki nilai ambang batas ISBB. Hasil pengukuran yang telah dilakukan di bagian IM1 PT.X Sidoarjo, yaitu pengukuran suhu kering (Sk), suhu basah alami (Sb), suhu bola/radiasi ( $\mathrm{Sg}$ ), kelembaban nisbi (Rh), menunjukkan bahwa iklim kerja di bagian IM1 PT.X Sidoarjo telah melebihi Nilai Ambang Batas (NAB) yang dianjurkan untuk pekerja dengan beban kerja sedang. Keadaan tersebut dapat mengakibatkan pengaruh terhadap produktivitas kerja dan timbulnya gangguan kesehatan tenaga kerja seperti dehidrasi.

Metode iklim kerja yang digunakan adalah metode Indeks Suhu Bola Basah (ISBB). Pengukuran iklim kerja di bagian IM1 PT.X dilakukan di tiga titik dengan tiga kali pengukuran yaitu pagi hari, siang hari dan sore hari, hal ini dilakukan untuk melihat rerata iklim kerja di bagian IM1 sepanjang hari atau selama 8 jam kerja pada pekerja shift pagi. Pengukuran iklim kerja di bagian IM1 menghasilkan rerata sebagai berikut, suhu kering (Sk) $32,02^{\circ} \mathrm{C}$, suhu basah $(\mathrm{Sb}) 27,20^{\circ} \mathrm{C}$, suhu bola/radiasi $(\mathrm{Sg})$ $32,91^{\circ} \mathrm{C}$ dan kelembaban $66,6 \%$.

Suhu kering (Sk) di bagian IM1 PT.X Sidoarjo sebesar $32,02^{\circ} \mathrm{C}$ telah melebihi Nilai Ambang Batas (NAB) yang dianjurkan, yaitu $21-30^{\circ} \mathrm{C}$. Suhu kering yang dapat dilihat dari respon fisiologi tenaga kerja pada saat kerja, yaitu berupa keluhan terasa panas dan gangguan kesehatan berupa banyaknya keringat yang keluar oleh tenaga kerja terutama pada saat bekerja. Suhu panas dapat mengurangi kelincahan dalam bergerak, memperpanjang waktu reaksi dan waktu pengambilan keputusan, mengganggu kecermatan kerja otak, mengganggu koordinasi saraf perasa dan motoris (Suma'mur, 2009).

Pengukuran iklim kerja di bagian IM1 PT.X dilakukan di tiga titik dengan 3 kali pengukuran yaitu pagi hari, siang hari, sore hari. Hal ini dilakukan untuk melihat rerata iklim kerja di bagian IM1 sepanjang hari atau selama 8 jam kerja pada pekerja shift pagi. Hasil pengukuran iklim kerja di bagian IM1 PT.X Sidoarjo menghasilkan nilai ISBB terendah $28,40^{\circ} \mathrm{C}$ dan tertinggi $29,50^{\circ} \mathrm{C}$, kondisi tersebut tidak nyaman karena 
seharusnya ISBB yang diperkenankan untuk beban kerja sedang yaitu maksimal $28,0^{\circ} \mathrm{C}$ (Permenakertrans No.Per.13/MEN/X/201).

Iklim kerja yang panas di bagian IM1 PT.X Sidoarjo salah satu faktor penyebabnya ialah berasal dari mesin produksi yaitu mesin injection moulding yang berjumlah 14 mesin, masing-masing mesin menghasilkan panas dari proses produksi yang secara otomatis tenaga kerja harus selalu berdekatan dengan sumber panas tersebut. Ventilasi ruangan berupa kipas angin yang jumlahnya tidak sebanding dengan luas area IM1 dan hanya diletakkan dititik tertentu saja, selain itu cuaca panas pada siang hari juga berpotensi mengakibatkan iklim kerja di IM1 menjadi panas. Hal tersebut mengakibatkan terjadinya peningkatan produksi keringat dan seringnya tenaga kerja merasa haus.

\section{Tingkat Dehidrasi Pekerja Shift Pagi bagian Injetion Moulding 1}

Pengukuran tingkat dehidrasi pekerja di bagian IM1 PT.X Sidoarjo menggunakan pemeriksaan berat jenis urinn pekerja. Metode berat jenis urin dipilih karena mudah dilakukan, sering digunakan, waktu analisis singkat, ketepatan baik dan rendahnya risiko bagi subyek yang diperiksa. Berat jenis urin tidak tepat bila digunakan pada subyek yang menderita diabetes mellitus, demam dan sindrom nefrotik karena dapat mempengaruhi nilai berat jenis urin, namun hal tersebut sudah dipertimbangkan melalui pemilihan subyek melalui kriteria inklusi. Pengambilan sampel urin dilakukan setelah 6 jam bekerja dengan menggunakan botol bening yang telah disediakan oleh peneliti. Pemeriksaan berat jenis urin dilakukan di laboratorium Dinas Kesehatan Kota Surabaya.

Hasil pemeriksaan berat jenis urin menunjukkan bahwa hanya terdapat satu pekerja yang memiliki status normal. Sisanya ditemukan pekerja mengalami pre dehidrasi (dehidrasi tingkat ringan 18 orang dan dehidrasi tingkat sedang 6 orang), sedangkan yang mengalami dehidrasi sebesar 6 orang pekerja.

Pre dehidrasi merupakan tahap awal sebelum benar-benar terjadinya kekurangan cairan atau dehidrasi, yang dikategorikan menjadi dehidrasi ringan dan dehidrasi sedang. Pada tahap dehidrasi ringan tubuh sudah mengalami kekurangan cairan sebesar 1 sampai dengan $2 \%$ dan mengalami tanda-tanda dehidrasi seperti haus, lemah, lelah, sedikit gelisah, dan hilang selera makan. Pada tahap dehidrasi sedang tubuh sudah mengalami kekurangan cairan sebesar 3 sampai dengan $4 \%$ dan mengalami tanda-tanda dehidrasi seperti kulit kering, mulut dan tenggorokan kering, volume urin kurang. Pada tahap dehidrasi, tubuh sudah mengalami kekurangan cairan 5 sampai dengan $6 \%$ dan mengalami tanda-tanda dehidrasi seperti sulit berkonsentrasi, sakit kepala, kegagalan pengaturan suhu tubuh serta peningkatan frekuensi nafas. Kehilangan cairan $>6 \%$ meningkatkan risiko gangguan kesehatan, seperti dapat mengakibatkan otot kaku dan collapse, saat tubuh kehilangan cairan sebesar $7 \%$ sampai dengan $10 \%$ dapat menurunkan volume darah serta berakibat kegagalan fungsi ginjal saat tubuh kehilangan cairan sebesar 11\% (Gustam, 2012).

\section{Analisis Hubungan antara Umur Pekerja dengan Tingkat Dehidrasi Pekerja}

Umur pekerja memiliki hubungan yang lemah dengan tingkat dehidrasi pekerja dibagian Injection Moulding 1 PT. X Sidoarjo. Umur pekerja yang sebagian besar $\leq 40$ tahun pada saat dilakukan penelitian ini tidak terlalu mempengaruhi tingkat dehidrasi yang dialami oleh pekerja shift pagi bagian Injection Moulding 1 PT. X Sidoarjo. Umur pekerja $\leq 40$ tahun tergolong masih muda yang secara teori masih dapat mentolerir pengaruh suhu tinggi, karena pada usia muda lebih sedikit menyerap panas dan lebih cepat beraklimatisasi. Sehingga kemungkinan untuk terjadi dehidrasi pada pekerja yang berumur $\leq 40$ tahun sangat kecil kemungkinannya. Namun setelah diuji secara statistik, hal tersebut tidak cukup kuat untuk membuktikan bahwa umur pekerja langsung berhubungan dengan kejadian dehidrasi pada pekerja tersebut. Hal ini karena umur bukanlah satusatunya faktor yang kuat sebagai penyebab dehidrasi pada pekerja shift pagi bagian Injection Moulding 1. Selain itu pada variabel umur pengkatagorian jenis umur bersifat homogen sehingga dapat menyebabkan nilai koefisien korelasi kecil. Pada dasarnya dehidrasi bisa menyerang siapa saja, dari anak kecil hingga orang tua. Namun yang paling rentan terkena dehidrasi adalah anak kecil dan orang tua. Tubuh anak kecil mengandung banyak lemak dan lemak hanya mengandung air lebih kurang 20 persen. Sementara itu, pada tubuh orang tua, kadar air dalam tubuhnya sudah semakin menurun akibat proses penuaan organ-organ tubuh (Handoyo, 2014).

\section{Analisis Hubungan antara Masa Kerja dengan Tingkat Dehidrasi Pekerja}

Masa kerja pekerja memiliki hubungan yang lemah dengan tingkat dehidrasi pekerja di bagian Injection Moulding 1 PT. X Sidoarjo. Semakin lama orang terpapar panas, semakin besar pula kemungkinan untuk mendapat keluhan kesehatan (Siswanto, 1991). Tenaga kerja yang baru bekerja di tempat panas maka akan kesulitan untuk menyesuaikan diri dengan lingkungannya. Tenaga kerja harus beradaptasi dengan cara beraklimatisai dengan suhu di tempat kerja. Setiap calon tenaga kerja yang akan bekerja di lingkungan tempat kerja panas harus melakukan penyesuaian fisiologis terhadap pajanan panas secara bertahap. Proses penyesuaian ini tidak saja bagi tenaga kerja baru, tetapi juga berlaku bagi tenaga kerja yang sudah lama bekerja di lingkungan tempat kerja panas yang sudah 9 hari atau lebih absen dari tempat kerjanya (Soeripto, 2008).

Sejalan dengan teori yang dikemukakan oleh Adiningsih (2013), masa kerja dengan waktu yang cukup lama dapat diasumsikan bahwa tenag kerja sudah terampil dalam melakukan pekerjaannya, jenis kegiatan yang dilakukan selalu sama sehingga menimbulkan kebiasaan. 
Semakin lama masa kerja seseorang, maka semakin besar pemaparan panas yang diterimanya sehingga mengakibatkan pekerja mengalami gangguan kesehatan salah satunya adalah dehidrasi. Menurut Suma'mur (2009), menyatakan bahwa masa kerja menentukan lama paparan seseorang terhadap faktor risiko yaitu tekanan panas.

\section{Analisis Hubungan antara Waktu Istirahat Pekerja dengan Tingkat Dehidrasi Pekerja}

Waktu istirahat pekerja memiliki hubungan yang lemah dengan tingkat dehidrasi pekerja dibagian Injection Moulding 1 PT. X Sidoarjo. Perbedaan waktu istirahat diantara pekerja menjadikan pekerja mengalami tingkat dehidrasi yang berbeda pula. Perusahaan sendiri sudah menyediakan waktu istirahat yang sesuai denggan kondisi beban kerja pekerja yaitu selama satu jam. Pekerja yang tergolong memiliki beban kerja ringan dan dilakukan selama 8 jam kerja, waktu istirahat yang dianjurkan untuk pekerja tersebut adalah satu jam.

Secara teori seharusnya pekerja yang memiliki waktu istirahat cukup akan memiliki resiko gangguan kesehatan lebih kecil dibandingkan dengan pekerja yang memiliki waktu istirahat kurang. Namun dalam penelitian ini tidak terbukti bahwa pekerja yang memiliki waktu istirahat cukup akan berisiko mengalami dehidrasi. Hal ini dapat terjadi karena pada pekerja yang memiliki waktu istirahat cukup belum tentu memiliki tingkat konsumsi air minum yang sesuai. Faktor-faktor terjadinya dehidrasi pada pekerja yang bekerja di iklim yang panas tidak hanya bergantung pada waktu istirahat pekerja saja, banyak faktor lainnya yang mempengaruhi. Sehingga tidak menutp kemungkinan bahwa pekerja yang memiliki waktu istirahat cukup akan terhindar dari risiko kejadian dehidrasi.

\section{Analisis Hubungan antara Konsumsi Air Minum Pekerja dengan Tingkat Dehidrasi Pekerja}

Konsumsi air minum pekerja memiliki hubungan yang lemah dengan tingkat dehidrasi pekerja dibagian Injection Moulding 1 PT. X Sidoarjo. Pekerja yang mengonsumsi air minum sesuai dengan kebutuhan tubuh maka akan memiliki status hidrasi yang baik, namun pekerja yang asupan cairannya tidak memenuhi kebutuhan dapat mengalami dehidrasi (Armstrong, 2007). Selama musim panas atau bilamana pekerja terpapar lingkungan panas, air minum harus disesuaikan dengan kebutuhan tenaga kerja sedemikian rupa sehingga mereka dapat minum secara teratur dan banyaknya air minum yang dikonsumsi 1 gelas setiap 15-20 menit (kira-kira 150 $\mathrm{ml})$. Penambahan garam pada minuman pekerja sebaiknya sudah betul-betul larut sebelum dibagikan dan air sebaiknya disimpan di tempat yang cukup dingin $10^{\circ} \mathrm{C}$ $15^{0} \mathrm{C}$.

Ketentuan mengenai rekomendasi konsumsi air minum diperjelas oleh Siswanto (1991), orang yang bekerja di tempat panas harus minum sesering mungkin (200 s.d $300 \mathrm{cc}$ air tiap 30 menit sekali). Hal ini bertujuan agar cairan tubuh tetap dalam keadaan seimbang. Namun ukuran 200 sampai dengan $300 \mathrm{cc}$ air tiap 30 menit sekali tersebut bukan menjadi patokan bahwa pekerja harus minum air sebanyak itu, melainkan yang terpenting adalah anjuran untuk minum air sesering mungkin untuk semua ukuran walaupun tidak 200 sampai dengan $300 \mathrm{cc}$ air. Penelitian Andayani (2013) membuktikan bahwa asupan cairan berpengaruh signifikan terhadap status hidrasi pekerja. Hanya $28,8 \%$ pekerja yang memiliki status hidrasi baik. Sisanya mengalami pre dehidrasi (dehidrasi ringan $37 \%$ dan dehidrasi sedang 15\%), sedangkan yang mengalami dehidrasi sebesar 19,2\%. Subyek yang mengkonsumsi cairan sesuai kebutuhan hanya $2,7 \%$.

Hidrasi di tempat kerja perlu mendapatkan perhatian khusus karena hidrasi dapat mempengaruhi biaya, produktivitas, dan keselamatan kerja. Ada banyak manfaat yang didapat jika tubuh terhidrasi dengan baik dan ketika sedang sibuk bekerja, perlu dipastikan bahwa asupan cairan yang masuk dalam tubuh cukup (Derbyshire, 2011). Menurut Miller dan Bates (2009), memastikan bahwa pekerja memiliki asupan cairan yang cukup merupakan cara intervensi yang paling efektif untuk menjaga kesehatan dan produktivitas pekerja selama bekerja.

\section{Analisis Hubungan antara Iklim Kerja dengan Tingkat Dehidrasi Pekerja}

Pengukuran iklim kerja di bagian Injection Moulding 1 PT.X Sidoarjo dihasilkan sebanyak $87,1 \%$ pekerja mengalami dehidrasi baik kategori dehidrasi ringan dan sedang, maupun kategori dehidrasi pada kondisi indeks suhu basah dan bola yang melebihi nilai ambang batas. Terdapat pekerjaan yang dilakukan dengan posisi berdiri sehingga dapat meningkatkan beban kerja dan mempengaruhi kondisi iklim kerja yang dapat diterima. Sebanyak 55,5\% pekerja mengalami pre dehidrasi tingkat ringan, sebanyak $18,5 \%$ pekerja mengalami pre dehidrasi tingkat sedang dan sebanyak $22,3 \%$ pekerja mengalami dehidrasi pada kondisi iklim kerja yang melebihi nilai ambang batas. Suhu lingkungan yang tinggi merangsang tubuh untuk berkeringat sebagai proses alamiah guna menurunkan suhu tubuh hingga pada suhu tubuh normal $\left(36^{\circ} \mathrm{C}\right.$ sampai dengan $\left.37^{\circ} \mathrm{C}\right)$. Pengeluaran keringat yang banyak tanpa diimbangi dengan asupan cairan yang cukup akan mengakibatkan dehidrasi yang juga bisa berakibat pada timbulnya kelelahan (Tarwaka dkk,2004).

Indeks suhu bola dan basah di bagian IM1 PT.X Sidoarjo menunjukkan angka sebesar antara $28,40^{\circ} \mathrm{C}-$ $29,50^{\circ} \mathrm{C}$. Angka tersebut masih berkisar pada angka $28^{\circ} \mathrm{C}$ sehingga dirasa masih cukup nyaman meskipun ditemukan pekerja yang mengalami pre dehidrasi dan dehidrasi. Hal ini terjadi karena selain merasakan panas lingkungan sekitar juga menghasilkan panas dari metabolisme tubuhnya. Berdasarkan permasalahan ini sebaiknya perusahaan menambah ventilasi udara yang ada di tempat kerja. Ventilasi udara yang ada saat ini berupa 
kipas angin yang hanya terletak pada beberapa titik tertentu saja. Penempatan kipas angin dapat diatur sedemikian rupa sehingga seluruh pekerja dapat merasakan aliran udara segar.

Menurut perhitungan secara statistik tingkat keeratan atau besarnya hubungan antara variabel iklim kerja terhadap variabel tingkat dehidrasi pekerja shift pagi di bagian Injection Moulding 1 dapat dilihat pada Symmetric Measures, yaitu pada koefisien korelasi sebesar 0,204. Berarti bahwa hubungan kedua variabel tersebut adalah lemah. Iklim kerja yang panas mempunyai hubungan dengan tingkat dehidrasi pekerja yang bekerja di lingkungan kerja panas tersebut. Penelitian di Australia pada pekerja tambang dengan suhu lingkungan kerja $36,2^{\circ} \mathrm{C}$ menunjukkan bahwa $60 \%$ pekerja shift bekerja dalam keadaan dehidrasi (BJU > 1,022 g/ml). Penelitian lain di Australia pada pekerja outdoor menunjukkan bahwa $79 \%$ pekerja mengalami dehidrasi (BJU > 1,021 $\mathrm{g} / \mathrm{ml}$ ). Penelitian pada pekerja laundry dengan paparan panas suhu $30,1^{\circ} \mathrm{C}$ sampai dengan $33,3^{\circ} \mathrm{C}$ menunjukkan bahwa 50 dari 70 sampel atau $71,7 \%$ terbukti mengalami clinically dehydrated dengan $\mathrm{BJU} \geq 1,030 \mathrm{~g} / \mathrm{ml}$.

Andayani (2013), dalam penelitiannya mengungkapkan bahwa suhu tinggi di lingkungan kerja $\left(>30^{\circ} \mathrm{C}\right)$ dapat menjadikan pekerja yang bekerja di lingkungan tersebut mengalami dehidrasi. Sebanyak $37,0 \%$ pekerja mengalami pre dehidrasi tingkat ringan, $15 \%$ pekerja mengalami pre dehiddrasi tingkat sedang dan $19,2 \%$ pekerja mengalami dehidrasi. Penelitian yang dilakukan Sari (2014), memberikan hasil yang sama, yaitu ada pengaruh yang signifikan $(p=0,023$ dan $\alpha=0,05)$ antara iklim kerja panas terhadap dehidrasi pada tenaga kerja bagian boiler di PT. Albasia Sejahtera Mandiri Semarang. Pengukuran ISBB di bagian boiler rata-rata sebesar $32,0^{\circ} \mathrm{C}$ dan tenaga kerja yang mengalami dehidrasi sebanyak 10 responden dari 15 responden. Hasil penelitian tersebut mendukung hasil penelitian yang dilakukan di bagian Injection Moulding 1 PT. X Sidoarjo bahwa antara iklim kerja dengan tingkat dehidrasi memiliki hubungan.

\section{KESIMPULAN DAN SARAN}

Hasil penelitian menunjukkan bahwa pengukuran iklim kerja dibagian Injection Moulding 1 telah melebihi NAB untuk beban kerja sedang yaitu ISBB maksimal yang dapat diterima pekerja sebesar $28^{\circ} \mathrm{C}$. Hasil pengukuran tingkat dehidrasi pekerja shift pagi dibagian Injection Moulding 1 sebagian besar pekerja mengalami pre dehidrasi ringan. Ada hubungan yang lemah antara iklim kerja dengan tingkat dehidrasi pekerja shift pagi dibagian Injection Moulding 1.

Saran yang dapat diberikan kepada perusahaan antara lain penambahan minuman elektrolit (larutan oralit) atau penambahan garam pada air minum pekerja sebagai pengganti cairan tubuh yang hilang dan meningkatkan fasilitas perusahaan untuk mempermudah pekerja dalam mengakses air minum, seperti penambahan jumlah dispenser dan penambahan jumlah gelas yang disediakan disesuaikan kebutuhan pekerja, hal ini bertujuan untuk menghindari tertularnya penyakit.

\section{DAFTAR PUSTAKA}

Adiningsih, R. 2013. Faktor yang Mempengaruhi Kejadian Heat Strain pada Tenaga Kerja yang Terpapar Panas di PT.Aneka Boga Makmur. The Indonesian Journal of Occupational Safety and Health. Vol 2. No. 2 Juli - Desember 2013 : 145-153.

Andayani, K. 2013. Hubungan Konsumsi Cairan dengan Status Hidrasi Pekerja Industri Laki-Laki. Skripsi. Semarang: Fakultas Kedokteran Universitas Diponegoro.

Armstrong, L.E. 2007. Assessing Hydration Status: The Ellusive Gold Standart. Journal of American College of Nutririon. 26(5) :575-584.

Brake, dan Bates. 2003. Fluid Losses and Hydration Status of Industrial Workers under Thermal Stress Working Extended Shifts. Occup Environ Med. 60; 90-96.

Derbyshire, E. 2011. Hydration at Work. United Kingdom: Natural Hydration Council.

Gustam. 2012. Faktor Risiko Dehidrasi pada Remaja dan Dewasa. Skripsi. Departemen Gizi Masyarakat Fakultas Ekologi Manusia Institut Pertanian Bogor.

Handoyo, Koko. 2014. Khasiat \& Keajaiban Air Putih. Jakarta : Dunia Sehat.

Miller, dan Bates. 2007. Hydration of Outdoor Workers in North-West Australia. Occupational Health and Safety. 23(1): 79-87.

Peraturan Menteri Tenaga Kerja dan Transmigrasi Nomor 13 Tahun 2011 tentang Nilai Ambang Batas Faktor Fisika dan Faktor Kimia di Tempat Kerja, Jakarta : Kementerian Tenaga Kerja \& Transmigrasi.

Puspita, AD. 2015. Iklim Kerja dan Beban Kerja Terhadap Tingkat Dehidrasi Pekerja Shift Pagi bagian Injection Moulding 1 PT.X.

Sidoarjo. Skripsi. Surabaya : Fakultas Kesehatan Masyarakat Universitas Airlangga.

Sari, NP. 2014. Pengaruh Iklim Kerja Panas terhadap Dehidrasi \& Kelelahan Tenaga Kerja bagian Boiler di PT.Albasia Sejahtera Mandiri. Skripsi. Semarang: Fakultas Ilmu Kesehatan Universitas Muhammadiyah.

Siswanto, A. 1991. Tekanan Panas. Surabaya: Balai HIPERKES dan Keselamatan Kerja.

Soeripto, M. 2008. Higiene Industri. Balai Penerbit Fakultas Kedokteran Universitas Indonesia.

Suma'mur. 2009. Higiene Perusahaan \& Kesehatan Kerja (HIPERKES). Jakarta : CV. Sagung Seto.

Suma'mur, PK. 1988. Higiene Perusahaan dan Keselamatan Kerja. Jakarta : CV Haji Mas Agung .

Tarwaka, Solichul H.A. Bakri, Lilik Sudiajeng. 2004. Ergonomi - untuk Keselamatan, Kesehatan Kerja dan Produktivitas. Jakarta : Penerbit buku Kedokteran. 